\title{
İnsansız Hava Araçları İçin Görüntü İşleme Tabanlı Otonom İniş
}

\author{
Mustafa İlker Ekmen ${ }^{1}$, Ömer Aydoğdu ${ }^{2}$ \\ ${ }^{1}$ Konya Teknik Üniversitesi, Mühendislik ve Doğa Bilimleri Fakültesi, Elektrik-Elektronik Mühendisliği Bölümü, Konya, Türkiye (ORCID: 0000-0002-0573-6717) \\ ${ }^{2}$ Konya Teknik Üniversitesi, Mühendislik ve Doğa Bilimleri Fakültesi, Elektrik-Elektronik Mühendisliği Bölümü, Konya, Türkiye (ORCID: 0000-0003-0815-0356)
}

( $1^{\text {st }}$ International Conference on Computer, Electrical and Electronic Sciences ICCEES 2020 - 8-10 Ekim 2020)

(DOI: 10.31590 /ejosat.804502)

ATIF/REFERENCE: Ekmen, M. İ. \& Aydoğdu, Ö. (2020). İnsansız Hava Araçları İçin Görüntü İşleme Tabanlı Otonom İniş. Avrupa Bilim ve Teknoloji Dergisi, (Özel Sayı), 297-303.

\section{$\ddot{O} \mathbf{z}$}

Günümüzde teknolojik anlamda herkes güvenli ölçümlerin hayatımızdaki etkisine oldukça aşinadır. Yani bu bağlamda araştırmacılar tarafından güvenli ölçüm çalışmaları için birçok çalışma yapıldı ve bunlardan biri İnsansız Hava Aracı. İnsansız Hava Aracının iyi bilinen bir kullanımı, belki de, bu cihazı sadece insansız hareketi için değil, aynı zamanda keyfi alanlar üzerinde uçuş sırasında benzersiz manevra için son derece pratik kılan güvenlik ve bakım ölçümlerindeki kabiliyetidir. Bu araştırmada İnsansız Hava Aracının otomatik inişi ele alınmıştır.

İnsansız Hava Araçlarının (IHA) günümüzde gözetleme, keşif, askeri amaçlar, taşımacılık, zirai ilaçlama, kamera çekimi, yangın söndürme gibi birçok alanda kullanımı hızla artmıştır. İHA sistemlerinde kalkış, seyir, güdüm ve iniş kontrolü en önemli olaylardır. İHA'nın seyir halinde havadaki dengesi, çevre güvenliği ve uçuş stabilitesi açısından önem arz etmektedir. İHA'nın kalkış ve iniş manevraları güvenlik ve kararlılık açısından oldukça önemlidir. Bu çalışmada, havadaki bir İHA'nın görüntü işleme metodları kullanılarak zemin üzerindeki renkli bir alana otonom olarak inmesi sağlanmıştır. Alan üzerine dairesel biçimde bir cisim konulmuş̧ur. Bunun için renkli dairesel cismin kamera ile koordinatları ölçülerek bu koordinatlara göre iniş yörüngesi belirlenmiştir. Kamera ile çekilen görüntü 512 piksele ayrılmıştır. Çekilen görüntünün tam orta noktası $256 \times 256$ pikseller olarak ayarlanmıştır. Kameradan gelen anlık geri kazançlar ile İHA kendi konumunu sürekli kontrol ederek sabit kalmaya çalışmıştır. Bu sayede otonom iniş için gerekli olan anlık kontrol edilen değerler kamera görüntüsü kullanılarak değerlendirilmiştir. Ayrıca çalışmada İHA için eşdeğer lineer bir transfer fonksiyonu elde edilmiştir. İHA’nın giriş sinyallerinin ve çıkış sinyallerinin değerleri incelenerek System identification ile uygun bir transfer fonksiyonu elde edilmiştir. Bu transfer fonksiyonu denetleyici tasarımında kullanılmıştır.

\section{Image Processing Based Autonomous Landing for Unmanned Aerial Vehicles}

\begin{abstract}
Technologically, everyone today is very familiar with the impact of safe measurements on our lives. In this context, many studies have been done by researchers for safe measurement studies, and one of them is Unmanned Aerial Vehicle. A well-known use of the Unmanned Aerial Vehicle is perhaps its ability in safety and maintenance measurements, which makes this device extremely practical not only for unmanned movement but also for unparalleled maneuvering during flight over arbitrary areas. In this research, the automatic landing of the Unmanned Aerial Vehicle is discussed.

The use of Unmanned Aerial Vehicles (UAV) in many areas such as surveillance, reconnaissance, military purposes, transportation, agricultural spraying, camera shooting and fire fighting has increased rapidly. Take-off, navigation, guidance and landing control are the most important events in UAV systems. The balance of the UAV in the air while traveling is important in terms of environmental safety and flight stability. The take-off and landing maneuvers of the UAV are very important in terms of safety and stability. In this study, an airborne UAV was enabled to land autonomously on a colored area on the ground using image processing methods. An object
\end{abstract}

\footnotetext{
${ }^{1}$ Sorumlu Yazar: Konya Teknik Üniversitesi, Mühendislik Fakültesi, Elektrik-Elektronik Mühendisliği Bölümü, Konya, Türkiye, ORCID: 00000002-0573-6717, ilkerekmen99@gmail.com
} 
is placed in a circular shape on the field. For this, the coordinates of the colored circular object were measured with the camera and the landing trajectory was determined according to these coordinates. The image taken with the camera is divided into 512 pixels. The exact midpoint of the captured image is set to $256 \times 256$ pixels. With the instant gains from the camera, the UAV tried to stay stable by constantly checking its position. In this way, the instantly controlled values required for autonomous landing were evaluated using the camera image. In addition, an equivalent linear transfer function was obtained for the UAV. and output signals of the UAV, a suitable transfer function has been obtained with System identification. This transfer function is used in controller design.

Keywords: Autonomous Fligh, System Identification, Image Processing

\section{Giriş}

Günümüzde İnsansız Hava Araçları (IHA) askeri ve sivil ortamlarda oldukça fazla kullanılmaya başlanmıştır. Özellikle son zamanlarda otonom olarak belirli bir noktaya giden veya bir cismi otonom bir şekilde takip eden İHA çalışmaları yapılmaktadır. İHA'nın gerçekleştirmekte olduğu göreve göre otonom hareketinde hedef noktaya göre sapmaların oldukça minumum olması gerekmektedir. Örneğin belli bir nokta üzerine otonom bir şekilde iniş yapması beklenen bir İHA'nın beklentinin uzağında bir noktaya inmesi halinde belirlenen görevi başarıyla gerçekleştirememesine sebebiyet verecektir. Otonom sistemler için en önemli nokta sistemin matematiksel modelinin en iyi şekilde ortaya çıkarılması ve bu matematiksel modele göre uygun denetleyici katsayılarının belirlenmesidir. Günümüzde halen İHA sistemleri için en yaygın kullanılan denetleyiciler PID denetleyicilerdir. Denetim amacıyla kullanılan PID denetleyici katsayılarının belirlenmesinde farklı yöntemler mevcuttur. Bunlara Ziegler Nichols ve yapay zeka yöntemleri örnek verilebilir.

Literatürde İHA sistemleri için Harmel ve arkadaşları geri-adım kontrol yöntemi kullanarak İnsansız Hava Aracı denge sistemi geliştirmek için başarılı bir simülasyon programı gerçekleştirerek deney sonuçları elde etmişlerdir.[1]. Bouabdallah ve arkadaşları İHA üzerinde birden çok kontrol yöntemi deneyerek PID kontrol yöntemini OS4 deneyi üzerinde başarıyla uygulayarak dengeli bir uçuş elde etmişlerdir[2]. Kutluk Bilge Arıkan ve ekibi tarafından gerçekleştirilen bir çalışmada yükseklik kontrolünü LQR (linear-quadratic regulator) ve yönelim kontrolünü PID kontrol algoritması ile sağlayan dengeli uçabilen bir sistem elde etmişlerdir [3].

İHA'lar için iniş teknikleri incelendiğinde açık havada inişin, rüzgâr, görüş mesafesi, vb. gibi harici rahatsız edici faktörlerin varlığından dolayı daha zorlu bir sorundur. Görüş tabanlı inişlerin ana kısmı, cisim algılama veya zemin tanıma teknikleri kullanarak iniş pistini tespit etmektir. Bu, aşağıda verilen birkaç yaklaşım kullanılarak yapılabilir.

Image Segmentation: Bir görüntünün piksel kümelerine bölünmesini ve görüntüdeki her piksele aynı etikete sahip piksellerin baz1 görsel özellikleri paylaşacağı şekilde bir etiket atamasını içerir. Bu daha sonra görüntüdeki çizgileri, nesne sınırlarını ve eğrileri tanımlamak için kullanılabilir. Eşikleme, gri tonlamalı bir görüntüyü ikili görüntüye dönüştüren en kolay görüntü bölümleme yöntemlerinden biridir [4].

Image Moments: Görüntü işlemede görüntü anı, görüntü piksellerinin yoğunluklarının ağılıklı ortalaması veya bu tür anların bir fonksiyonudur. Bunların genellikle bazı özel nitelikleri ve yorumları vardır. Genellikle segmentasyondan sonra nesneleri tanımlamak için kullanılırlar [4].

Monocular Vision: Binoküler görmeden farklı olarak her gözün ayrı ayrı kullanıldığı, böylece görüş alanını artıran ancak derinlik algısını sinırlayan bir tekniktir [4].

Stereo Vision: İki bakış noktasından bir sahne hakkındaki bilgiler karşılaştırılır, ardından nesnelerin göreceli konumlarının incelenmesiyle 3B bilgiler çıkarılabilir [4].

Bu çalışmada, dört pervaneli insansız hava aracının dengeli bir şekilde iniş pozisyonuna geçerek görüntü işleme algoritmaları kullanılarak belirlenen alanın üzerine hata payı minumum olacak şekilde inmesi için çalışma yapılmışır. Görüntü işleme yöntemi; çekilmiş olan bir resmin dijital olarak bilgisayar ve yazılım desteği ile işlenmesi uygulaması olarak tanımlanmaktadır. Görüntü işleme uygulamaları başlangıçta askeri ve güvenlik amacıyla kullanılmakta iken günümüzde sürdürülebilir birçok meslek alanında kendine yer bulmaktadır [5]. Görüntü işleme için doğru yöntemin karar verilmesinin ardından ideal bir işleme programının seçilmesi (Matlab, phyton gibi) ve verilerin işlenmesi gerçekleştirilmektedir. İşleme gerçekleştikten sonra elde edilen verilerin yorumlanması ve kullanılması gerekmektedir. Teknolojik gelişmeler ile birlikte elde edilen veriler sadece daha sonra kontrol edilmeyip anlık değerlendirmeler ile de (real time) kullanılabilmektedir [6]. Çalışmada İHA'nın matematiksel modeli Matlab System Identification Toolboxı kullanılarak belirlenmeye çalışılmıştır.

\section{Materyal ve Metot}

\subsection{Modelleme ve Kontrol}

İHA sistemleri üzerlerine yerleştirilen dört adet motorun hareket ettirilmesi ile elde edilen itki kuvvetinin yardımıyla hareketini gerçekleştirirler. Dört adet motor ile üç adet konum ve üç adet yönelim durumunu denetlemesi gereken İHA, bu yapısı ile doğrusal 
olmayan bir modele sahiptir. Motorların hareketi ile durumlar arasında bir bağ olan ve bu durumun bozucu bir etki oluşturduğu İHA'nın denetlenmesi zordur [7].

System Identification kullanılarak PID katsayıların belirlenmesinde en önemli faktör matematiksel modeli tespit edilecek sistemin giriş ve çıkış değerleridir. $\mathrm{Bu}$ çalışmada görüntü işleme algoritmaları kullanılarak zeminde tespit edilen bir cismin üzerine dengeli bir şekilde İnsansız hava aracı indirilmeye çalışılmıştır. İHA'lar üzerine yapılan modelleme çalışmalarından bir tanesi P. Pounds ve arkadaşlarının geliştirdiği, 'X-4 Flayer' ismini verdikleri hava aracı tasarımı ve doğrusal modelinin elde edilmesidir. Bu sistemde açısal konumu korumak amacıyla elde edilen doğrusal tek giriş tek çıkışlı modelde PID denetleyici kullanılmıştır [8].

Matlab Simulink ortamında oluşturulan model de ilk girilen değerler sistemin giriş (Input) değerleri olacaktır. Bu değerler referans olarak kabul edilecektir. Cismin, İHA üzerinde bulunan kameraya göre hangi noktada bulunması gerektiği bu değerler ile ifade edilmektedir. Görüntü işleme algoritmaları ile kameranın gösterdiği alan X ve Y ekseni boyunca 512 pikseldir. Cismin kameranın tam orta noktasında bulunması gerektiği için yapılan çalışmada referans değeri olarak X ekseninde 256 ve Y ekseninde 256 piksel noktalarında cismin bulunası gerekmektedir. Referans değerlerine göre İHA'nın PID katsayıları olmadan iniş pozisyonuna geçerek ne kadar sapma meydana getirdiği uçuş yapılarak incelenmiştir. Aynı zamanda PID katsayıları olmadan gerçekleştirilen uçuşun X ve $\mathrm{Y}$ eksenindeki piksel değerleri yaklaşık 0.1 saniye aralıklar ile kayıt altına alınmıştır.

Matlab Simulink ortamında oluşturulan modele Giriş (Input) ve Çıkış (Output) değerleri girilmiş ve grafiksel sonuçlar alınarak gerçekleştirilen uçuşun referans değerlere göre yaptığ 1 hata incelenmiştir. System Identification toolbox kullanılarak X ve Y eksenlerine göre ayrı ayrı transfer fonksiyonları elde edilmiştir. 9 iterasyon sonucunda sistem girilen değerlere en uygun transfer fonksiyonunu ortaya çıkarmıştır.

Elde edilen transfer fonksiyonu Simulink ortamında oluşturulan matematiksel modele entegre edilerek, Matlab ortamında PID denetleyici için en uygun katsayılar elde edilmiştir. Sistem PID denetleyici olmadan yapılan uçuş ve PID denetleyici ile uçuş durumlarında çalıştırılarak giriş ve çıkış değerleri grafiksel olarak elde edilmiş ve iki durum karşılaştırılmıştır.

\subsection{Görüntü İşleme ve İniş Yeri Tespiti}

İniş algılama sistemi, aracın inmesi için belirlenen yeri kesin olarak belirler. Yerden bir nesneyi tanır ve nesnenin dairesel şekillere sahip olup olmadığını kontrol etmek için geometrik ve kenar algılama algoritmaları kullanır. İniş yerimizi tanımlayan dairesel şekillerin çıkarılması, yüksek kaliteli görüntü yerine kullanılabilir.

$\mathrm{Bu}$ çalışmada ilk olarak, İHA üzerinde bulunan kamera ile cismin piksel üzerindeki konumları ölçülmektedir. Cismin piksel konumları X ve Y ekseni olarak ayrı ayrı ölçülerek İHA’nın cisme göre ileride, geride, sağda veya solda olduğu tespit edilmektedir. Daha sonra X ve Y eksenleri belirli histogram oluşturularak değerlendirilir. Geometrik hesaba dayalı Histogram, yatay ve dikey yönlerde değerlenir; benzer şekilde Öklid mesafesi ile de yapılabilir. Bu dizi, vektörlerin derecesini elde etmek için her piksel için ikili formatta yürütülür. Her histogram için, model özelliği Mj ve görüntü özelliği I arasındaki eşleşme derecesi Dj şu şekilde hesaplanır [9].

$$
D_{j}=\sum_{i=1}^{n} \sqrt{I_{i} M_{j i}}
$$

İkili formatın geometrik histogramından dolayı, başka bir hesaplama kenar tespiti olacaktır. Görüntüyü dönüştürmek için Öklid mesafesine özel algoritma kullanılır. Öncelikle 2B görüntüler için algoritma, görüntü çözünürlügünü $\mathrm{X}$ ve Y yönlerinde ayırt eder ve kenar pikselleri tanımlanmalıdır. İkinci olarak, her kenar piksel için tam bir metrik mesafe vardır, bu nedenle metriğin her pikseli, ikili görüntünün eşleşen bir alanıyla ilişkilendirilir ve ikili format görüntüde en yakın pikselleri elde etmek için Öklid mesafesi aracıllğıyla bir mesafe değeri atanır [9]. 2D görüntüdeki iki piksel noktası $\mathrm{P}(\mathrm{x} 1, \mathrm{y} 1)$ ve $\mathrm{Q}(\mathrm{x} 2, \mathrm{y} 2)$ için klasik Öklid mesafesi L aşağıda tanımlanan denklem (2) ile hesaplanır[9].

$$
\mathrm{L}=\sqrt{\left(x_{2}-x_{1}\right)^{2}+\left(y_{2}-y_{1}\right)^{2}}
$$

Arka plan mesafesini Öklid mesafe formülasyonu ile çıkarmak için, görüntü çözünürlüğü X ve Y boyutlarında kullanılır, bu nedenle yukarıdaki ifade,

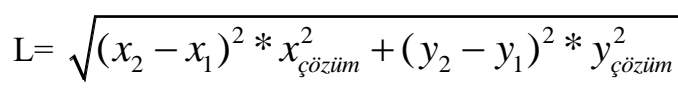

olarak yazılır. Bu formüller, görüntüdeki iki alan için uygulanır. Kameradan alınan görüntüdeki arka plan ve dairesel şekiller.

Bu değerler İHA'nın referans noktasına göre oluşan hata değerlerinin de tespit edilmesini sağlamıştır. Şekil 9'da Matlab kullanarak örnek bir daire uygulamasının sonucu gösterilmektedir. 


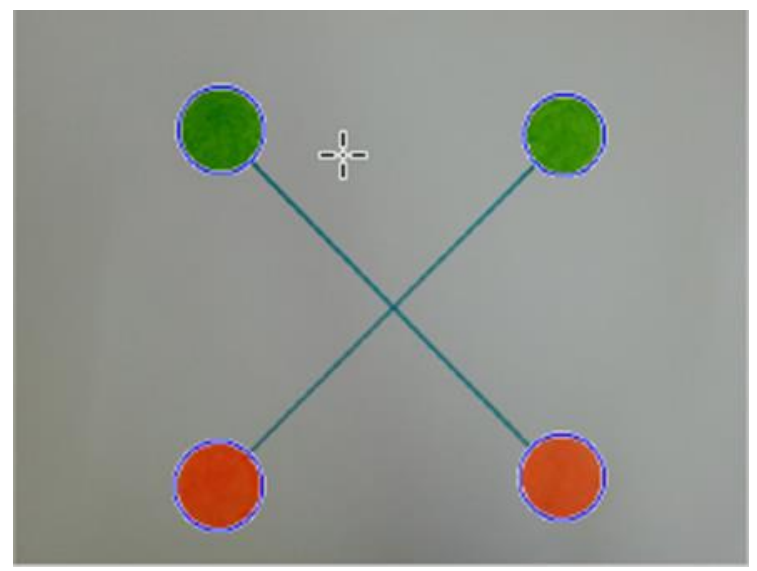

Şekil 1. İHA için daire tespiti [9]

\section{Araştırma Sonuçları ve Tartışma}

\subsection{Deneysel Sonuçlar}

Çalışmada deneysel modelleme için veriler Şekil 2'de verilen blok diyagramı ile elde edilmiştir. Şekil 2'de simülasyon ortamına girilen Giriş ve Çıkış verilerinin dışa aktarılması için IDDATA Sink bloğu kullanılmıştır. Bu sayede dışa aktarılan data verisi System Identification Toolbox'ina kolay bir şekilde entegre edilecektir.

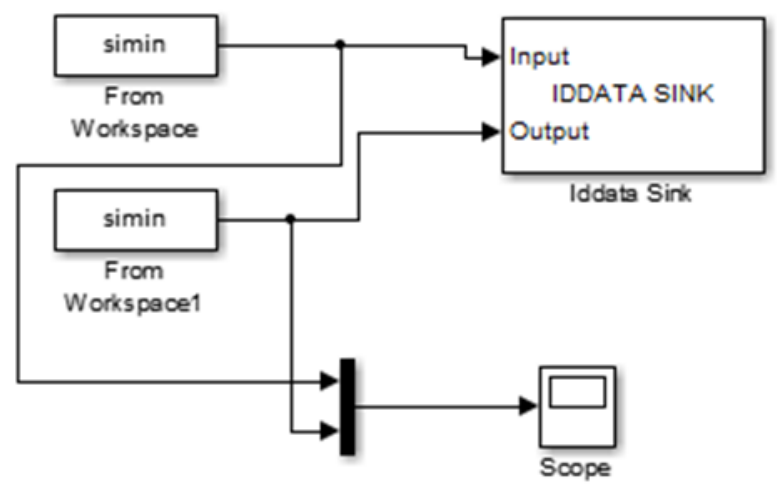

Şekil 2. Simülayon Verilerinin Dışa Aktarımı

Cismin kameraya göre olan X ve Y eksenlerindeki referans noktalarının listesi 0.1 saniye aralıklar ile Tablol 1'de gösterilmektedir.

Tablo 1. X ve Y Ekseni Üzerindeki Referans Değerler

\begin{tabular}{|r|r|r|}
\hline \multicolumn{1}{|l|}{ Time } & Data: 1 & Data:2 \\
\hline $2.5119 \mathrm{e}-06$ & 256 & 256 \\
\hline $1.5071 \mathrm{e}-05$ & 256 & 256 \\
\hline $7.7868 \mathrm{e}-05$ & 256 & 256 \\
\hline $3.9185 \mathrm{e}-04$ & 256 & 256 \\
\hline 0.0020 & 256 & 256 \\
\hline 0.0098 & 256 & 256 \\
\hline 0.0491 & 256 & 256 \\
\hline 0.1000 & 256 & 256 \\
\hline 0.2000 & 256 & 256 \\
\hline 0.3000 & 256 & 256 \\
\hline 0.4000 & 256 & 256 \\
\hline 0.5000 & 256 & 256 \\
\hline 0.6000 & 256 & 256 \\
\hline 0.7000 & 256 & 256 \\
\hline 0.8000 & 256 & 256 \\
\hline 0.9000 & 256 & 256 \\
\hline 1 & 256 & 256 \\
\hline
\end{tabular}


Tablo 1'de görüldüğü gibi kameranın ölçüm alanı 512 piksel olarak ayarlanmıştır. Ancak cismin kameranın tam orta noktasını referans alacağ

Tablo 2'de PID denetleyici olmadan gerçekleştirilen iniş aşamasının reel ortamdan alınan sonuçları gösterilmektedir.

Tablo 2. İnsansız Hava Aracı Üzerinden Ölçülen X ve Y Ekseni Değerleri

\begin{tabular}{|c|c|c|}
\hline 0 & 258 & 418 \\
\hline $2.5119 \mathrm{e}-06$ & 254 & 458 \\
\hline $1.5071 \mathrm{e}-05$ & 250 & 478 \\
\hline $7.7868 \mathrm{e}-05$ & 270 & 490 \\
\hline $3.9185 \mathrm{e}-04$ & 406 & 462 \\
\hline 0.0020 & 390 & 474 \\
\hline 0.0098 & 398 & 470 \\
\hline 0.0491 & 382 & 402 \\
\hline 0.1000 & 362 & 434 \\
\hline 0.2000 & 466 & 378 \\
\hline 0.3000 & 470 & 466 \\
\hline 0.4000 & 398 & 466 \\
\hline 0.5000 & 378 & 474 \\
\hline 0.6000 & 354 & 482 \\
\hline 0.7000 & 342 & 458 \\
\hline 0.8000 & 474 & 326 \\
\hline 0.9000 & 266 & 470 \\
\hline 1 & 226 & 366 \\
\hline
\end{tabular}

System Identification Toolbox'ı kullanılarak giriş ve çıkış değerlerinin sonuçlarına göre oluşturulan transfer fonksiyonları X ve Y eksenleri için ayrı ayrı aşağıdaki gibi elde edilmiştir.

$$
\begin{aligned}
& G x(s)=\frac{-0.8535 s+1.299}{s^{2}+1.337 s+0.7958} \\
& G y(s)=\frac{-0.8539 s+1.299}{s^{2}+1.337 s+0.7963}
\end{aligned}
$$

Elde edilen transfer fonksiyonları aşağıda Şekil 3'de görüldüğü gibi Simulinkte oluşturulan blok diyagramına entegre edilmiştir.

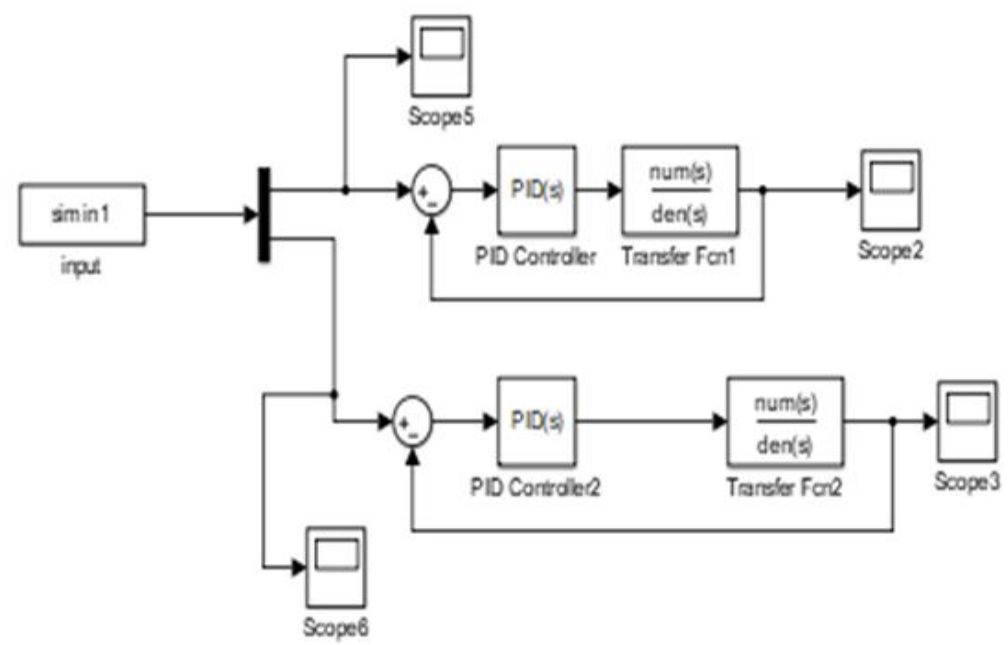

Şekil 3. Simülasyon Verilerininin Elde Edimesi 
Şekil 3'de oluşturulan modele göre çıkış sonuçları incelenmiş̧ir. PID denetleyici olmadan yapılan otonom inişin referans noktalara göre değişimi aşağıda Şekil 4'de gösterilmektedir.

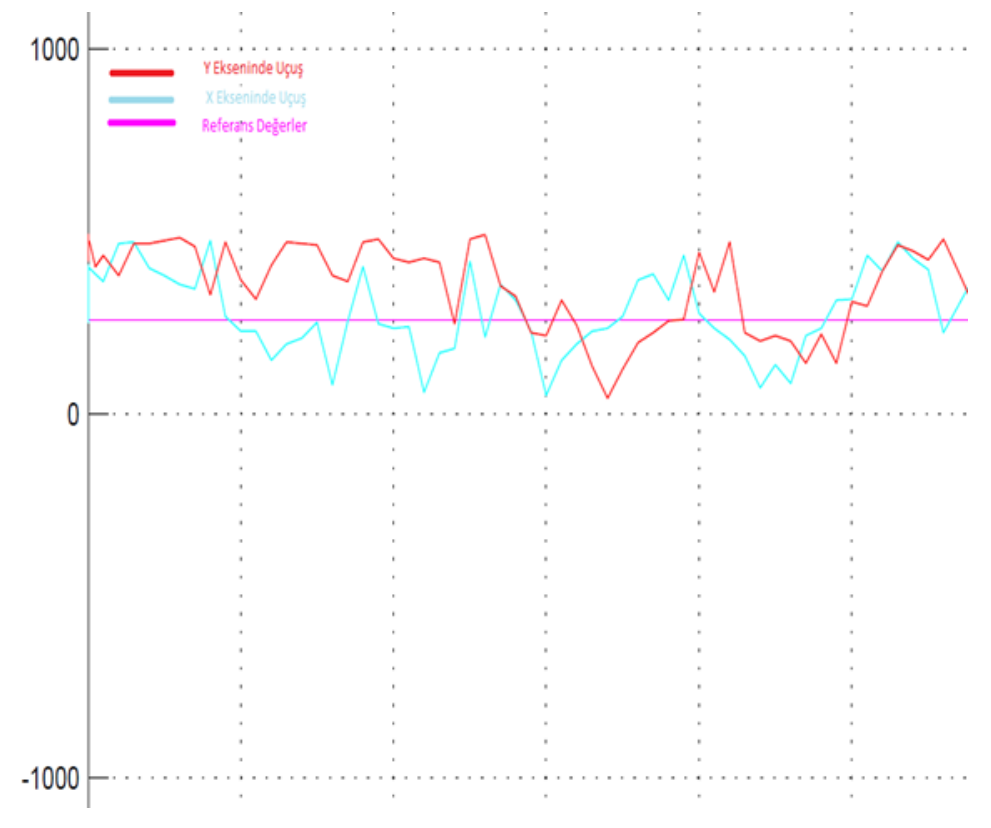

Şekil 4. Uçuş Değerlerinin Referans Değerlere Göre Değişimleri

Yukarıdaki sisteme PID denetleyici ilave edilerek optimal denetleyici parametreleri PID optimizasyon aracı kullanılarak Simulink ortamında elde edilmiştir. PID kontrol kullanılarak sistemin X ve Y eksenindeki çıkışları ayrı ayrı incelenmiştir. Şekil 5'de X ekseni üzerindeki simülasyon çıktıları gösterilmektedir. Şekil 6'da Y eksenine göre oluşan uçuş simülasyonunun çıkışları gösterilmektedir.

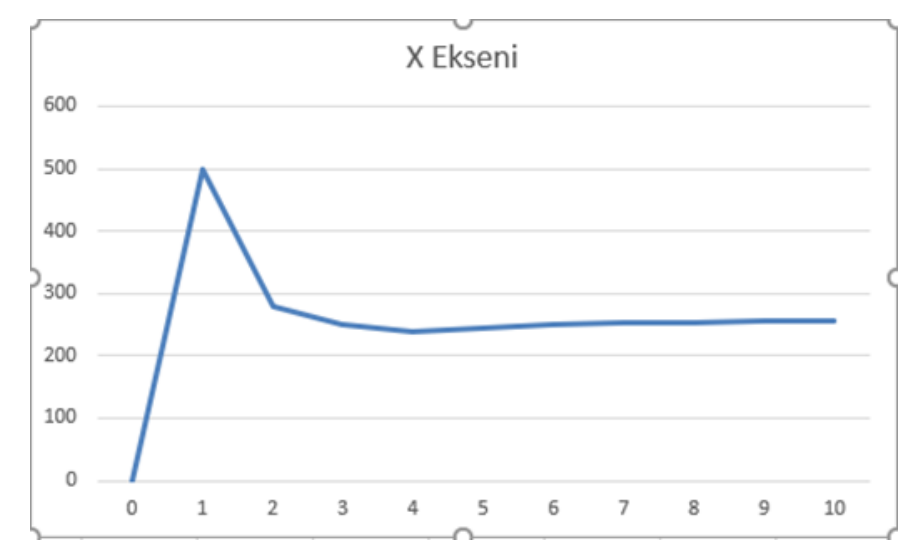

Şekil 5. Uçuş Sonrası X Ekseni İçin Zaman-Konum Grafiği

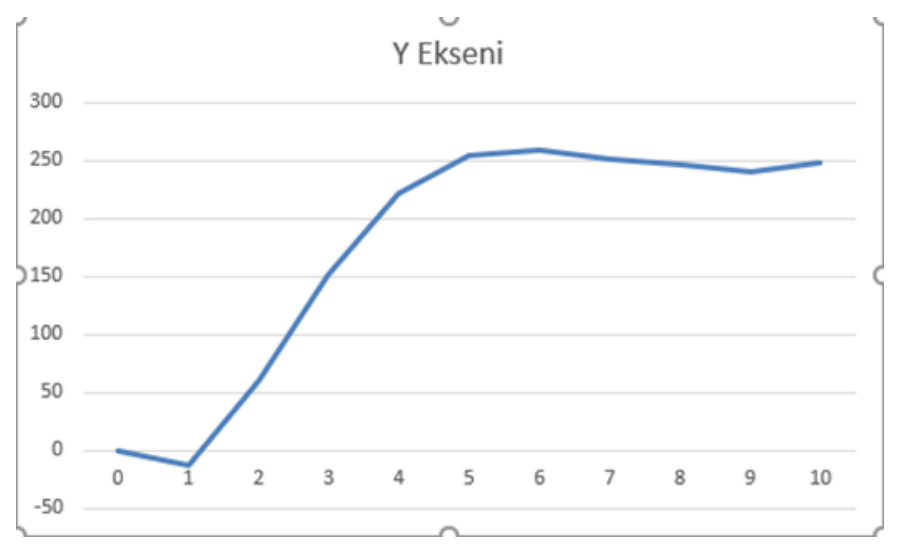

Şekil 6. Uçuş Sonrası Y Ekseni İçin Zaman-Konum Grafiği 


\section{Sonuç}

$\mathrm{Bu}$ çalışmada pratik olarak tasarlanan bir İHA için ilk olarak gerçek zamanlı uçuş verilerinden Giriş-Çıkış data kümeleri elde edilmiştir. Bu veriler kullanılarak Matlab Simulink ortamında System Identification toolbox'ı ile İHA için matematiksel model elde edilmiştir. Elde edilen matematiksel model geliştirilerek insansız hava aracının otonom bir şekilde inişinin gerçekleştirilmesinde kullanılabilecek seviyeye getirilmiştir. Elde edilen matematiksel model kullanılarak İHA kontrolü için bir optimal PID denetleyici tasarlanmış ve otonom iniş amacıyla başarıyla kullanılmıştır.

Ayrıca İHA için görüntü işleme tabanlı bir otonom iniş sistemi tasarlanmış ve kullanılan görüntü işleme yöntemi sayesinde rüzgârlı veya diğer diş etkenlere rağmen hafif bir sapma ile ineceği yeri doğru bir şekilde belirleyerek inişini gerçekleştirmiştir. Rüzgârlı veya diğer dış etkenler için uygulanan yöntemin geliştirilmesi gerekmektedir.

\section{Kaynakça}

[1] T. Hamel, R. Mahony, R. Lozano \& J. Ostrowski. (2002). "Dynamic Modelling and Configuration Stbilization for an X4-Flyer", 15th IFAC Triennial World Congress, Barcelona, Spain

[2] S. Bouabdallah, A. Noth \& R. Siegwart. (2004). "PID vs LQ Control Techniques Applied to an Indoor Micro Quadrotor", Proc. of 2004 IEEE/RSJ Int. Conf. on. Intelligent Robots and Systems, Japan.

[3] ] K.Bilge Arıkan \& A. Güçlü. (2012) " Attıtude And Altıtude Control Of An Outdoor Quadrotor "

[4] Alvika Gautam, P.B. Sujit \& Srikanth Saripalli. (2014) “A Survey of Autonomous Landing Techniques for UAVs", International Conference on Unmanned Aircraft Systems (ICUAS) May 27-30, Orlando, FL, USA

[5] Ağın O. \& Malaslı Z. (2016). Görüntü işleme tekniklerinin sürdürülebilir tarımdaki yeri ve önemi: Literatür çalı̧̧ması. Tarım Makinaları Bilimi Dergisi, 12 (3), 199-206.

[6] Şin B., Kadığlu İ. \& Sarı T. (2019). Detectıon and 1dentıficatıon of weed by image processing techniques. BIALIC, 7-8 Novamber, s. 40, Lviv Ukraine.

[7] Ahmet Demiryürek (2018). Bir Dört Pervanelinin Modellenmesi ve Denetimi, Hacettepe Üniversitesi Yüksek Lisans Tezi

[8] P. Pounds, R. Mahony \& P. Corke. (2010). "Modelling and control of a large quadrotor robot," Control Eng. Pract., vol. 18, no. 7, pp. 691699.

[9] Bahram Lavi \& Sahand Pourhassan Shamchi. (2014). “Auto Landing Process For Autonomous Flying Robot By Using Image Processing Based On Edge Detection”, Conference: International Conference on Foundations of Computer Science \& Technology 